\title{
A Study of Steel Bar Reinforcement Corrosion in Concretes with SF and SRH Using Electrochemical Impedance Spectroscopy
}

\author{
Fernanda Giannotti da Silva*, Jefferson Benedicto Libardi Liborio ${ }^{\mathrm{b}}$ \\ a'Department of Materials Engineering and Science, \\ University of São Paulo, São Carlos - SP, Brazil \\ ${ }^{\mathrm{b}}$ Department of Structure Engineering, University of São Paulo, São Carlos - SP, Brazil
}

Received: September 21, 2005; Revised: March 31, 2006

\begin{abstract}
Several electrochemical techniques can be used to monitor corrosion, among them are open circuit potential (OCP) and eletrochemical impedance spectroscopy (EIS). Monitoring OCP is the most typical procedure for routine inspection of reinforced concrete structures and can be easily carried out, however it only gives an approximate idea of the corrosion process. EIS is a more complete technique, which supplies information regarding the mechanism and kinetics of reaction electrochemistries, but only used in the laboratory. Based on these two techniques, this study is related to the steel corrosion in high-performance concrete with silica fume and silica from rice husk. The acceleration of the corrosion was carried out using immersion cycles in a $3.5 \%$ $\mathrm{NaCl}$ solution. As well as high compressive strength values, the addition of silica fume presented low corrosion risks and high impedance module values and significant increases of the concrete resistivity after 22 months of alternate immersion/drying cycles were obtained.
\end{abstract}

Keywords: high-performance concrete, silica fume, corrosion, eletrochemical techniques

\section{Introduction}

One of the worst problems related to civil building is steel corrosion in reinforced concrete structures. It is considered to be one of the worst and most frequent pathologies of civil building engineering and, as well as being a technical-economical-social problem, it still represents a great waste of natural resources ${ }^{1,2}$.

Embedded steel in concrete is protected against corrosion by two mechanisms: physical and chemical ${ }^{3,4}$. The chemical protection is guaranteed by high $\mathrm{pH}$ solution contained in the concrete pores (around 12.5), which causes steel passivation. The physical protection is guaranteed by concrete cover, which impedes aggressive agents reaching the steel.

With the aim of increasing the durability of concretes, new materials are being incorporated into the concrete to improve their properties such as porosity and especially permeability. Therefore, additions which are finer than the cement are being incorporated into the concrete, such as silica fume.

When added to the fresh concrete, silica fume reacts in two ways: a pozzolanic reaction and a filler effect. In the pozzolanic reaction, it reacts with the calcium hydroxide $(\mathrm{CH})$ chemically to produce an additional amount of calcium silicate hydrate $(\mathrm{C}-\mathrm{S}-\mathrm{H})$, which is responsible for the resistance of the concrete. There is an obstruction of concrete pores and a reduction of permeability ${ }^{4,5}$. Moreover, it still produces a filler effect, filling the spaces created by the free water in the cement matrix and packing the materials in a better way, whose property is due to extreme thinness of material (particles are 100 times smaller than cement grains) ${ }^{6}$.

Another factor should be mentioned: the ecological issue. These additions are residues from the manufacturing of silicon metal and ferrosilicon alloys, in the case of silica fume, and silica from rice husk, which are left in the air and pollute the environment ${ }^{7}$.

As well as endeavoring to have better durability of reinforced concrete structures, there is more and more research being done concerning the standardization of tests to analyse such parameters. Some international standards already recognize some items, however in Brazil there is still much to be done in this area.
Therefore, there are two main aims to this work: to verify the capacity of high-performance concrete in protecting the steel of concrete structures exposed to harsh environments, such as the sea, and to contribute to a larger knowledge of electrochemical techniques.

The open circuit potential technique is based on the potential differences of the measurement between metal and solution. Therefore, the voltage difference measurement is done between the steel bar and a reference electrode, placed in contact with the surface of the concrete ${ }^{1}$. The open circuit potential monitoring is a typical procedure in routine inspections of reinforced concrete structures when diagnosing corrosion. Its use and interpretation are described in the ASTM Standard Test Method for Half-Cell Potential of Reinforcing Steel in Concrete $^{8}$. In spite of being very used this method is qualitative, although it is not sufficient in the analysis of the corrosion process.

Furthermore, other techniques have been used when monitoring corrosion, such as electrochemical impedance spectroscopy. The impedance can measure the global physical resistance of metal in a specific environment, with a potential difference or imposed current in alternate signals, which is interpreted as resistive, capacitive and inductive components ${ }^{9,10}$. The larger the impedance of the system is, the more passive the system will be. In other words, the larger the restriction of the electrode to the current passage is and, consequently, the smaller the corrosion rate is. It offers some advantages in relation to the continuous current techniques: it uses very small signals that do not disturb the electrode properties to be measured, it studies corrosion reactions and estimates corrosion rates in low conductivity materials and it also determines the polarization resistance and the double layer capacitance in the same measurement ${ }^{11}$.

This technique has been used by an increasing number of researches in determining the corrosion rate of reinforcing steel in concrete. However, interpretation of an impedance spectrum is difficult due to the complexity of cement paste and concrete microstructural changes taking place on steel surfaces. Thus, it is necessary the development of studies related to electrochemical technique ${ }^{12,13}$. 


\section{Experimental}

\subsection{Production of concretes}

For the production of high-performance concrete analyzed in this work, the following materials were used: portland cement - $\mathrm{ABNT}^{14}$, whose chemical properties are shown in Table 1; silica fume and silica extracted from rice husk in volumetric partial substitution of portland cement in proportion of $10 \%$, whose chemical compositions are shown in Table 1; quartzous sand with a maximum diameter of $2.4 \mathrm{~mm}$; coarse aggregate of basaltic origin with a maximum diameter of $9.5 \mathrm{~mm}$ and superplasticizer admixture (SP) whose base is polycarboxylate, added at percentages from $0.4 \%$ to $1 \%$.

It is important to highlight that the studied silica fume is already used commercially and silica from rice husk is produced at the laboratory, whose process is described as follows. The rice husk is immersed in an acid solution, followed by washing it in water until the $\mathrm{pH}$ of the solution becomes neutral. After being dried, the husk is burnt, ground and burnt again at a temperature of $600{ }^{\circ} \mathrm{C}^{7}$, which makes the product white and amorphous (Figure 1).

Table 1. Chemical composition of portland cement, silica fume and silica from rice husk.

\begin{tabular}{lrcc}
\hline $\begin{array}{c}\text { Chemical } \\
\text { constituent }\end{array}$ & $\begin{array}{c}\text { Cement mass } \\
(\%)\end{array}$ & $\begin{array}{c}\text { Silica fume } \\
\text { mass }(\%)\end{array}$ & $\begin{array}{c}\text { Silica from rice } \\
\text { husk mass }(\%)\end{array}$ \\
\hline $\mathrm{SiO}_{2}$ & 21.16 & 95.92 & 97.53 \\
$\mathrm{Fe}_{2} \mathrm{O}_{3}$ & 1.89 & 1.33 & 0.21 \\
$\mathrm{Al}_{2} \mathrm{O}_{3}$ & 4.71 & - & - \\
$\mathrm{CaO}$ & 68.08 & 0.36 & 0.22 \\
$\mathrm{P}_{2} \mathrm{O}_{5}$ & 0.28 & - & 0.26 \\
$\mathrm{MgO}_{\mathrm{Na}} \mathrm{O}$ & 0.48 & 0.38 & - \\
$\mathrm{K}_{2} \mathrm{O}$ & 0.29 & 0.12 & 0.01 \\
Ignition loss & 0.48 & 0.30 & 0.04 \\
Insoluble & 2.39 & 1.58 & 1.72 \\
residue & 0.81 & - & - \\
\hline
\end{tabular}

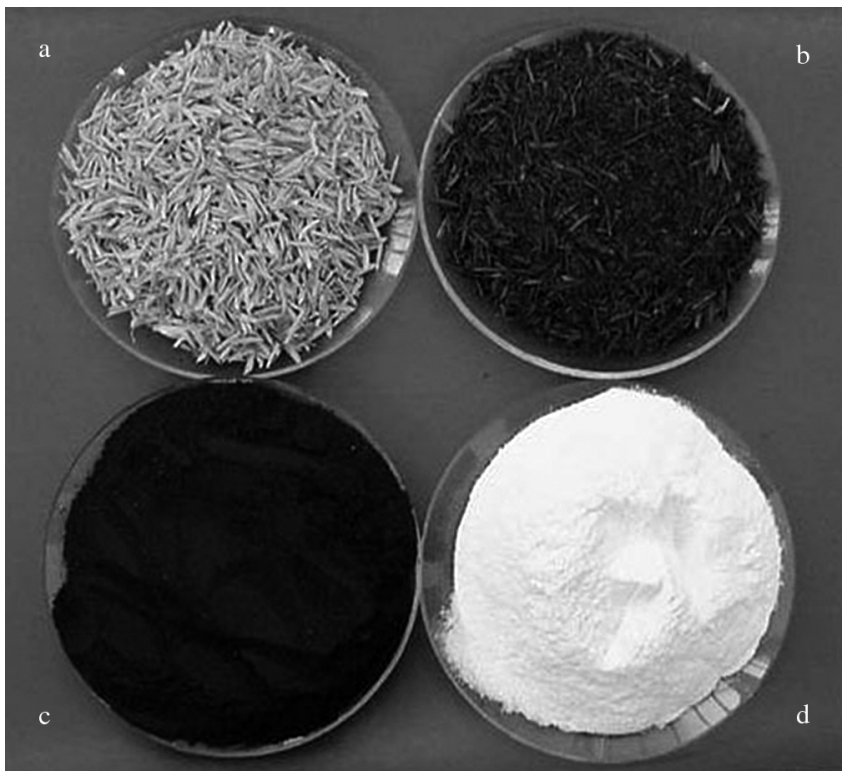

Figure 1. Phases of silica from rice husk production: rice husk a), rice husk ash before b) and after c) of grinding and silica from rice husk d).
The ratio of mixtures in this work is $1: 3.5$, being 3.5 the total of aggregates. The materials constituent used in the mixture is presented in Table 2.

After mixing the materials, the cylindrical and prismatic samples were prepared for the compressive strength and electrochemical tests, respectively. The cylindrical samples had a dimension of $5 \mathrm{~cm}$ diameter by $10 \mathrm{~cm}$ in height and the prismatic samples, $5 \mathrm{~cm} \mathrm{x}$ $5 \mathrm{~cm} \times 12 \mathrm{~cm}$. One commercial steel bar with a diameter of $1 \mathrm{~cm}$ was embedded in each prismatic sample, with a concrete cover of $2 \mathrm{~cm}$. The rest of the bar was sealed with insulating tape and the exposed rebar area was $9.42 \mathrm{~cm}^{2}$ (Figure 2).

The concretes were cured in a humid chamber kept at $95 \%$ of relative humidity and room temperature of $22 \pm 2{ }^{\circ} \mathrm{C}$. In the electrochemical tests, the samples were cured for 15 days and in the compressive strength tests, the samples were kept in the chamber until the test day. This period is the required time for the development of hydration reactions of material, mainly of the complete formation of $\mathrm{C}-\mathrm{S}-\mathrm{H}$, which is responsible for the resistance of concretes ${ }^{15}$.

\subsection{Exposure}

The prismatic samples were vertically immersed to a depth of $6 \mathrm{~cm}$ (partial immersion) in a 3.5\% $\mathrm{NaCl}$ solution. For 4 days a week, the samples were partially immersed in a $\mathrm{NaCl}$ solution and in the 4 subsequent days in a laboratory atmosphere. After the $19^{\text {th }}$ month of exposure, the solution concentration was increased from $3.5 \%$ to $10 \%$, with the objective of accelerating the penetration of chloride ions into the concrete.

Table 2. Mixture proportions and fresh concrete properties.

\begin{tabular}{lccc}
\hline & \multicolumn{3}{c}{ Concrete } \\
& Control & SF & SRH \\
\hline Cement $\left(\mathrm{Kg} / \mathrm{m}^{3}\right)$ & 503.3 & 454.9 & 451.4 \\
Silica fume $\left(\mathrm{Kg} / \mathrm{m}^{3}\right)$ & - & 33.7 & - \\
Rice husk silica & - & - & 35.0 \\
Total water $\left(\mathrm{Kg} / \mathrm{m}^{3}\right)$ & 176.2 & 171.0 & 170.2 \\
Superplasticizer $\left(\mathrm{Kg} / \mathrm{m}^{3}\right)$ & 2.52 & 2.93 & 5.84 \\
Coarse aggregate $\left(\mathrm{Kg} / \mathrm{m}^{3}\right)$ & 792.7 & 796.1 & 798.9 \\
Sand $\left(\mathrm{Kg} / \mathrm{m}^{3}\right)$ & 968.8 & 973.0 & 965.5 \\
Water/binder ratio & 0.35 & 0.35 & 0.35 \\
Fresh density $\left(\mathrm{Kg} / \mathrm{m}^{3}\right)$ & 2432 & 2417 & 2400 \\
\hline
\end{tabular}

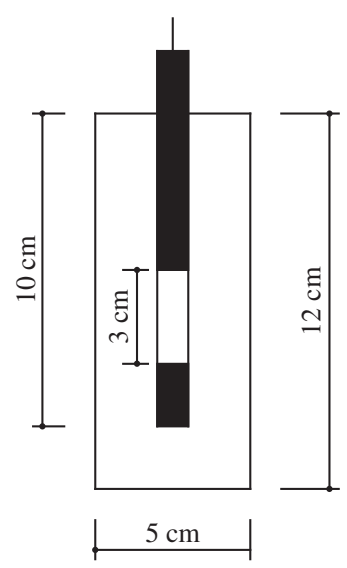

Figure 2. Scheme of the prismatic samples. Cover thickness $=2 \mathrm{~cm}$; steel bar diameter $=1 \mathrm{~cm}$. 


\subsection{Tests}

Concerning the description of the concretes, the compressive strength tests were done at the $1^{\text {st }}, 3^{\text {rd }}, 7^{\text {th }}, 28^{\text {th }}, 63^{\text {rd }}$ and $91^{\text {st }}$ days. Before the tests, all the samples were checked in order to have a better distribution of the load.

The open circuit potential measurements were taken using the reference electrode of copper/sulfate of copper. A sponge soaked in water and a detergent solution was used to increase the ionic conduction between the electrode and the concrete surface. The measurements were taken as close as possible to the steel using a high impedance voltmeter. All the potential measurements were taken across a concrete cover thickness of only $2 \mathrm{~cm}$, after the immersion period of the samples.

The electrochemical impedance spectroscopy test was carried out using a three- electrode system: the working-electrode consisting of the rebar, the reference electrode of copper copper/sulfate and counter electrode consisting of lead. The used equipment was a 1260 Solartron Impedance/Gain-Phase Analyser and 1287 Solartron Electrochemical Interface. Firstly, the $10 \mathrm{mV}$ sine wave was applied, however as the materials were very resistive the sine wave of $30 \mathrm{mV}$ was used, making sure that the system would not be damaged. In all the measurements the same conditions were adopted, with the purpose of preventing errors when comparing and interpreting the results.

\section{Results}

The compressive strength was tested in 4 samples on the $1^{\text {st }}, 3^{\text {rd }}$, $7^{\text {th }}, 28^{\text {th }}, 63^{\text {rd }}$ and $91^{\text {st }}$ days. The average results are given in Table 3 .

In the analysis of Table 3, it is observed that with the increase of age and silica fume presence, the compressive strength of concretes presented significant resistance increases.

When comparing the two silica types (SF and SRH), it was noticed that the difference of the values was small and there was a slight increase in the use of SF. This increase of resistance is associated to the largest efficiency of the silica fume and to the use of additive in its composition. The reaction of silica fume is due to the effect filler and to the pozzolanic reaction. Moreover, the additive reaction is responsible for better defloculation of cement grains and consequently an increase in the hydration rate.

The volumetric substitution of silica in the proposed content increased the maximum resistance by approximately $18 \%$ in relation to the concrete without silica considering the period of 91 days. Therefore, the use of silica fume and silica from rice husk reduces the consumption of cement to obtain the same resistance level.

The open circuit potential measurements for the test time provide qualitative information of corrosion, showing its probability of happening. In the graphs in Figure 2, potential values for immersion time are shown.

In Figure 3, the corrosion potential behavior of concretes with SF, SRH and concretes without silica can be observed. The potential values oscillate from - $188 \mathrm{mV}$ to $-62 \mathrm{mV}$. At the beginning of the cycles, the concretes with SF presented more positive potentials than the concretes with SRH, however it can be noticed that the difference decreased in the last cycles. After 22 months of partial immersion of samples in the $\mathrm{NaCl}$ solution, the potential still continues to be at low risk concerning the corrosion, according to ASTM C876 (Table 4), which may suggest passivation of the steel bar, although the above observation alone cannot be taken as conclusive evidence of the passive state of the steel.

It is important to emphasize that the potential oscillation is caused by drying/immersion cycles, in other words, by concrete humidity ${ }^{16}$. When the concrete surface is humidified, a decrease in the resistivity happens, increasing the current flow and changing the potential values.
Table 3. Compressive strength of hardened concrete.

\begin{tabular}{lcccccc}
\hline Mixture & \multicolumn{5}{c}{ Compressive strength (MPa) } \\
& 1 day & 3 days & 7 days & 28 days & 63 days & 91 days \\
\hline Control & 42.3 & 65.2 & 78.5 & 86.0 & 90.9 & 93.1 \\
SF & 45.4 & 68.7 & 83.3 & 103.2 & 107.7 & 110.4 \\
SRH & 45.8 & 65.0 & 86.9 & 99.5 & 105.8 & 109.2 \\
\hline
\end{tabular}

Table 4. ASTM criteria for corrosion of steel in concrete.

\begin{tabular}{cl}
\hline Copper/copper sulphate & \multicolumn{1}{c}{ Corrosion condition } \\
\hline$>-200 \mathrm{mV}$ & Low (10\% risk of corrosion) \\
$-200 \mathrm{mV} \mathrm{a}-350 \mathrm{mV}$ & Intermediate corrosion risk \\
$<-350 \mathrm{mV}$ & High $(<90 \%$ risk of corrosion) \\
$<-500 \mathrm{mV}$ & Severe corrosion \\
\hline
\end{tabular}

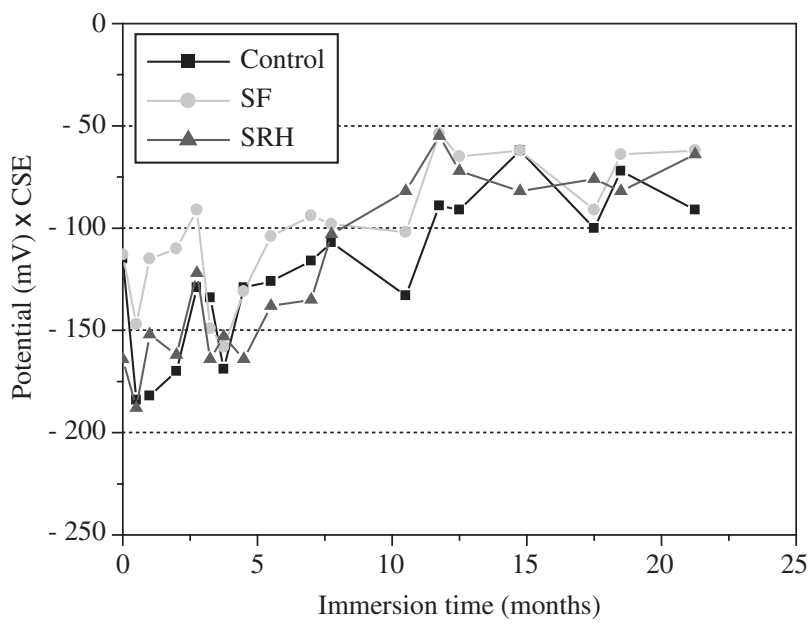

Figure 3. OPC evolution of concrete samples partially immersed in a $3.5 \%$ $\mathrm{NaCl}$ solution.

The results obtained by OPC were confirmed in the EIS, by Nyquist and Bode diagrams (Figures 4-6). The Nyquist complex plane graph is a plot of the resistive $Z_{\text {real }}$ against the capacitive $Z_{\text {imag }}$, while Bode diagrams are plots of the logarithm of the impedance modulus $\mathrm{Z}$ and phase angle against the logarithm of frequency.

In the Nyquist diagram, it can be observed that most of the spectra present similar characteristics, which are described by an electric resistance in series with a RC network (Figure 7). The series resistance $\left(R_{c}\right)$ accounts for a ionic conduction in the electrolyte filling the pores, whereas the other elements refer to the double layer capacitance at the steel/concrete interface $\left(\mathrm{C}_{\mathrm{d} 1}\right)$ and the charge transfer resistance $\left(\mathrm{R}_{\mathrm{ct}}\right)$.

In some cases, the Nyquist diagram presents a third semicircle in intermediate frequencies, as shown in Figure 5. This semicircle can suggest the formation of new products on the steel surface, among them the corrosion. However, the capacitive arch between $10^{4} \mathrm{~Hz}$ and $10 \mathrm{~Hz}$ is related to a fine deposit of calcium hydroxide that grows on the steel surface slowly after being immersed in concrete ${ }^{17}$, since the estimated diameter of the semicircle formed in high frequencies is extremely large. This indicates that the charge transfer resistance is very high $\left(>10^{6} \Omega\right.$ ) and could not be measured in the range of frequencies tested. 


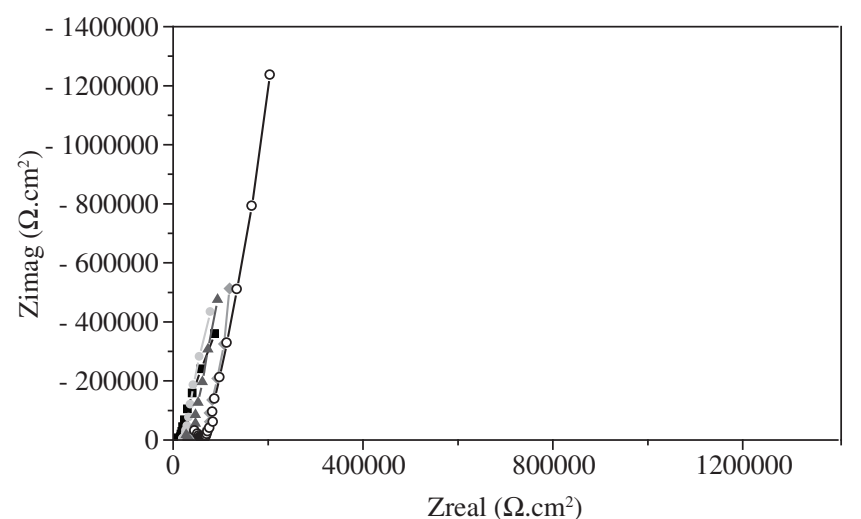

(a)

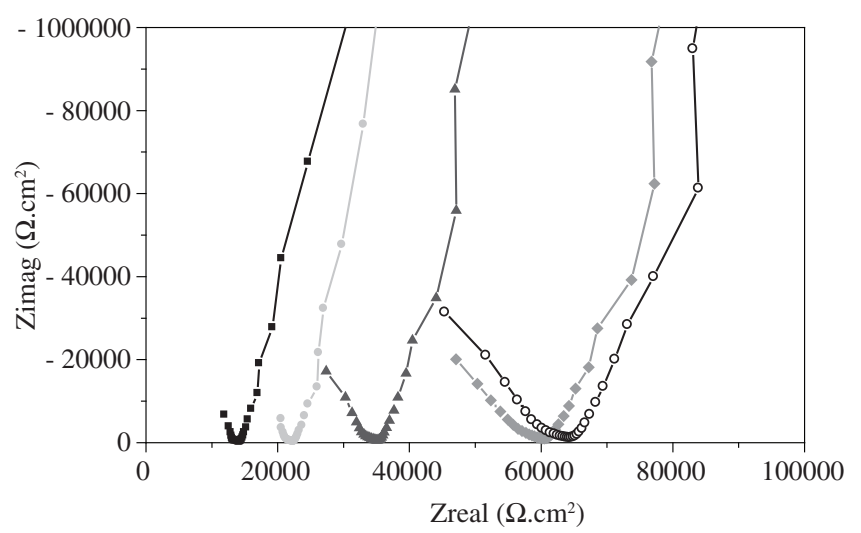

(b)
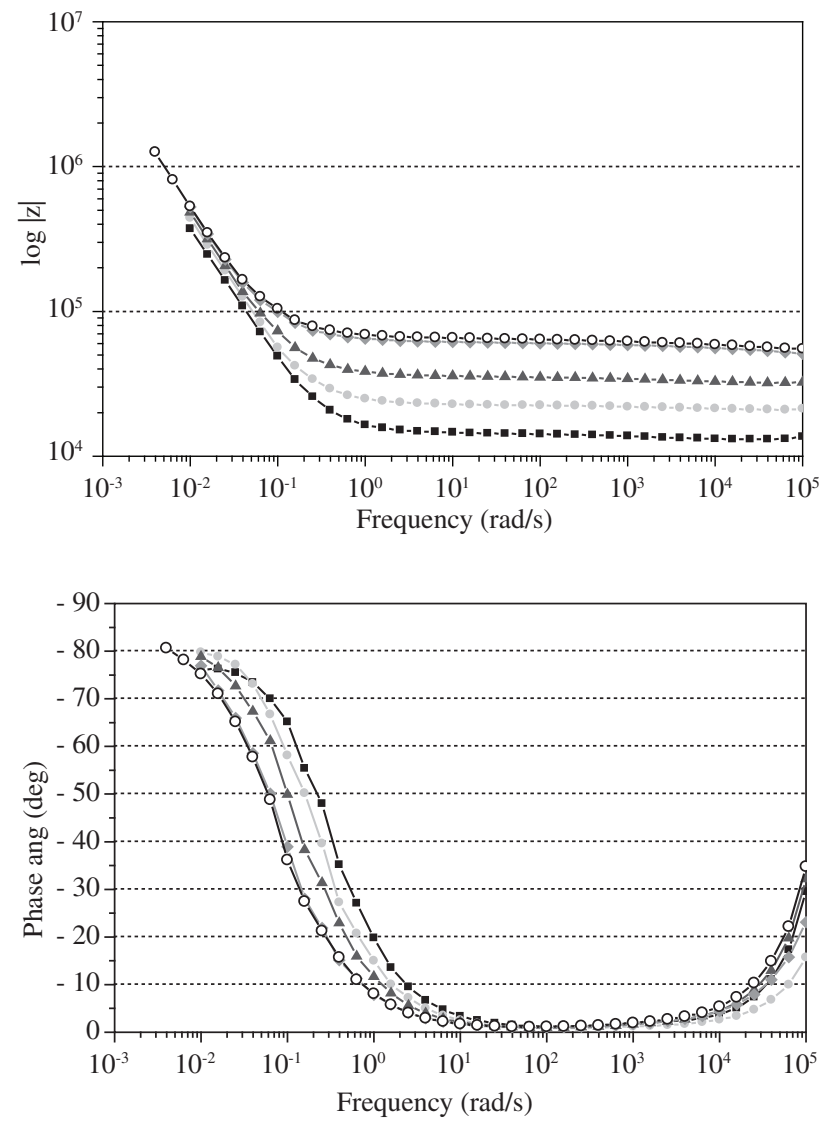

(c)

$\longrightarrow-$ without agression $\longrightarrow-\smile 8$ months $\multimap-022$ months
$\square-1$ month

Figure 4. Impedance spectra evolution of concrete sample without silica fume (control) during 22 months of immersion in $3.5 \%$ NaCl: a) Nyquist diagram; b) Nyquist diagram - high frequencies; and c) Bode diagrams.

Therefore, in general, all the bars analyzed in the concretes without silica or with SF or SRH are in a passive situation after 22 months of drying/immersion cycles in $\mathrm{NaCl}$ solution, according to potential readings.

It can be observed that throughout time and with the increasing number of cycles, the concrete resistivity increases (a shift to larger real impedance values). This increase is caused by the hydration and pozzolanic reactions of the material. Similar behaviors were obtained by Montemor et al. ${ }^{11}$, who monitored the corrosion of steel bars in concrete with fly ash by EIS. The increasing factor of resistivity for concretes without addition was 4 while for concretes with $50 \%$ of fly ash, in the same conditions, this fact was 40 .

The resistivity evolution for concretes studied in this work was different. Comparing Figures 4-6, the resistivity values of the concretes with SF were larger than the concretes with SRH and concretes without silica. After 22 months of analysis, the resistivity of concrete without silica and with SRH was from 4.1 to 4.7 times larger than the resistivity of the concrete before the cycles (for both cement types) and from 7.0 to 7.6 times larger than the concretes with SF, when compared to the initial resistivity (without aggression).

This difference can be seen better in Table 5, where the total impedance values are presented in the frequencies of $10^{2} \mathrm{rad} / \mathrm{s}, 10^{3} \mathrm{rad} / \mathrm{s}$ and $10^{4} \mathrm{rad} / \mathrm{s}$ for the first and last cycles. It can be highlighted that the adopted frequency values are only related to the resistive part of the material.

Analysing Table 5, it can be observed that the concretes present high total impedance values, especially in the cases in which SF is used. The high impedance values obtained suggest the passivity of the system, in other words, a larger restriction to the current flow.

Figure 8 presents the resistivity evolution of the concrete for the immersion time. The resistivity was estimated by the division of $|\mathrm{Z}|$ (see values shown in Table 5 for frequencies of $10^{4} \mathrm{rad} / \mathrm{s}$ ) for the thickness of the sample ${ }^{11}$.

The increase of concrete resistivity with an increase of immersion time can also be observed in the Bode diagrams of Figures 3-5 from $|\mathrm{Z}| v s$. the frequency. A shift can be observed for high values of $|\mathrm{Z}|$ in frequencies above $10 \mathrm{rad} / \mathrm{s}$. It can also be noticed that with the increase of the number of cycles, the resistive part of the material has ever decreasing lower frequencies, as Figure 3 clearly shows.

Still related to the first incomplete arch observed at high frequencies $\left(10^{4} \mathrm{rad} / \mathrm{s}\right.$ to $\left.10^{5} \mathrm{rad} / \mathrm{s}\right)$, it was not possible to estimate the capacitance of the dielectric properties of concretes as the obtained arch was incomplete and any extrapolation induces a high error. The increase in frequency is also not advisable as not only do the processes happen simultaneously in a given cell electrochemistry, but there is also still the possibility of the equipment being damaged by noise, 


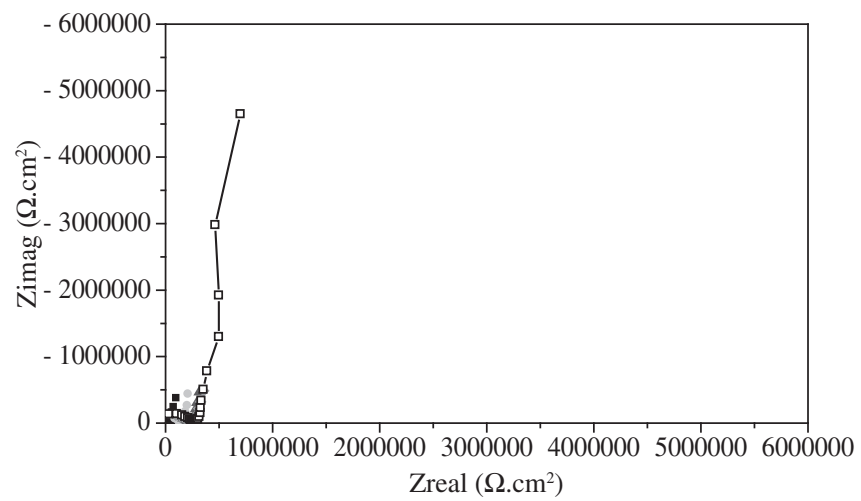

(a)

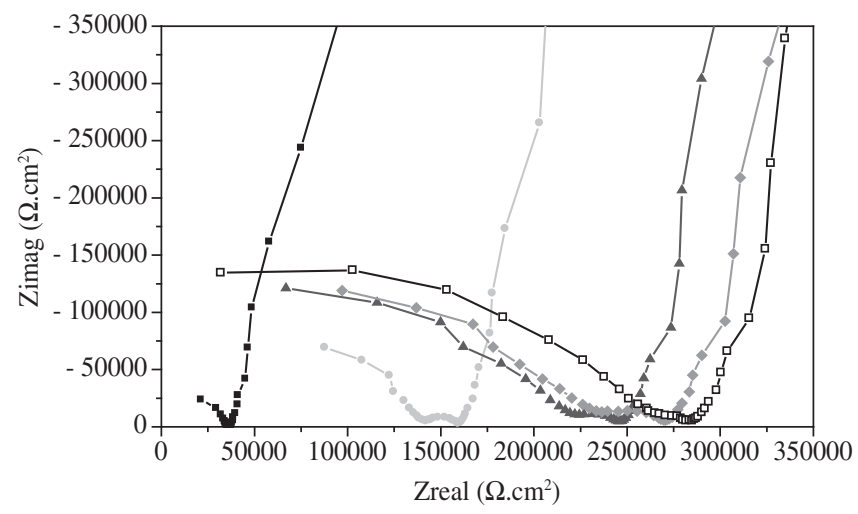

(b)
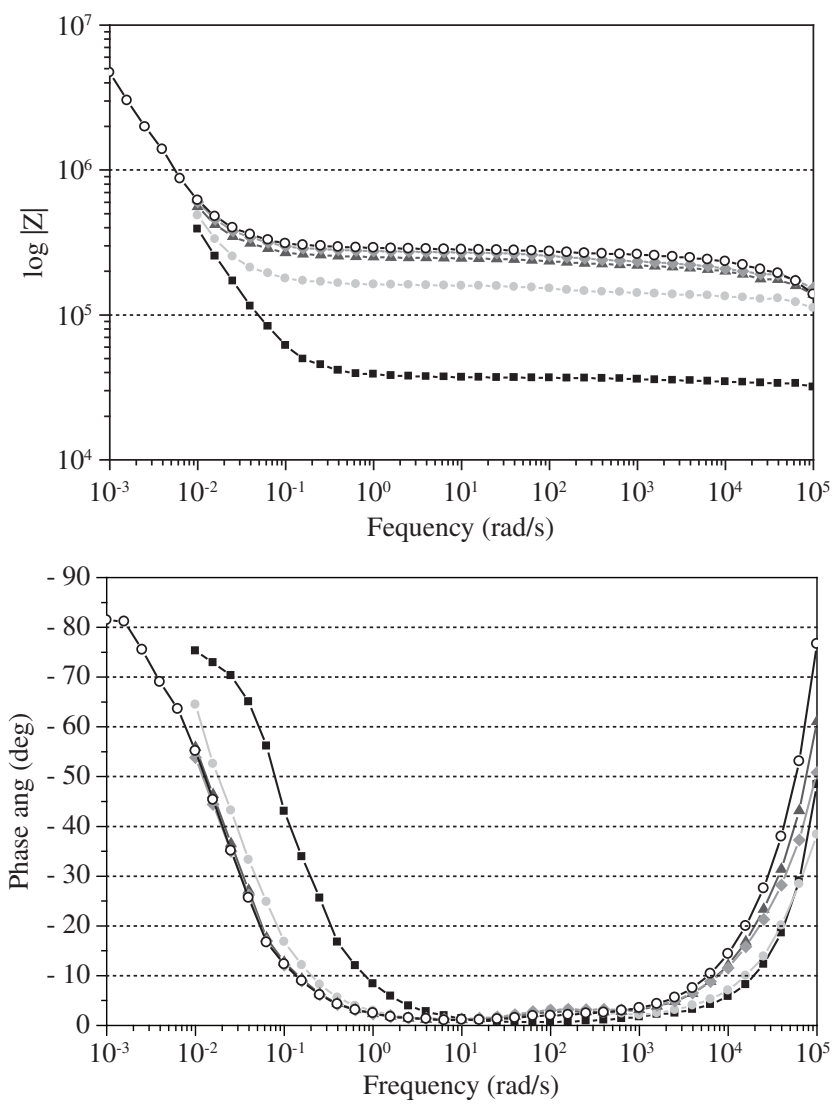

(c)

$\begin{array}{lll}\longrightarrow-\text { without agression } \longrightarrow-\backsim \text { months } & \longrightarrow 22 \text { months } \\ \longrightarrow-1 \text { month } & \longrightarrow 15 \text { months } \longrightarrow-22 \text { months }\end{array}$

Figure 5. Impedance spectra evolution of concrete sample with silica fume (SF) during 22 months of immersion in 3.5\% NaCl: a) Nyquist diagram; b) Nyquist diagram - high frequencies; and c) Bode diagrams.

Table 5. Total impedance values of concretes in $10^{2} \mathrm{rad} / \mathrm{s}, 10^{3} \mathrm{rad} / \mathrm{s}$ and $10^{4} \mathrm{rad} / \mathrm{s}$.

\begin{tabular}{llrrr}
\hline Concretes & \multicolumn{1}{c}{$\begin{array}{c}\text { Immersion time } \\
\text { (months) }\end{array}$} & \multicolumn{3}{c}{ Total impedance - $|\mathrm{Z}|$} \\
& \multicolumn{1}{c}{$10^{2} \mathrm{rad} / \mathrm{s}$} & $10^{3} \mathrm{rad} / \mathrm{s}$ & $10^{4} \mathrm{rad} / \mathrm{s}$ \\
\hline Control & Without agression & 14190 & 13774 & 13180 \\
& 1 & 22412 & 21942 & 21317 \\
& 22 & 63984 & 62028 & 58851 \\
\hline SF & Without agression & 36789 & 36039 & 34555 \\
& 1 & 152000 & 142000 & 134000 \\
& 22 & 274000 & 261000 & 234000 \\
\hline SRH & Without agression & 15635 & 15269 & 14444 \\
& 1 & 26378 & 25969 & 25287 \\
& 22 & 73187 & 70759 & 66916 \\
\hline
\end{tabular}

especially at high frequencies, where the capacitive arches can be affected by variations of the distance of the reference electrode to the work electrode, especially in materials of low conductivity ${ }^{18,19}$.

In Figures 4-6, it can be observed that there was no change in the behavior of samples at low frequencies, and there was no sign of any closing of the third arch, even after 22 months of partial immersion cycles in $\mathrm{NaCl}$ solution. This suggests a high polarization resistance, which is related to the arch diameter, and a smaller corrosion current density. Some extrapolation attempts were made, but the tendency of the points to form the semicircle is small, making the approximate determination of the values impossible.

In the Bode diagrams, the beginning of the corrosion can be observed by the change of inclination of $|\mathrm{Z}| v s$. frequency and by obtaining smaller phase angles related to the capacitive effect of double layer capacitance.

In the Bode diagrams it can be observed that not all the concretes have a defined maximum phase angle. In the concretes in which it is possible to identify the maximum phase angle, it can be seen that the same ones have close values to the increase of immersion time, and no significant decrease was observed.

\section{Conclusions}

The two methods studied in this work are valid when analyzing steel corrosion in concrete, however a complete analysis is necessary. The EIS showed some difficulties in making measurements and interpreting the results at the typically very low corrosion rate of passive reinforcements, especially in high-performance concrete due the time of analyses and equipment limitations (when the measurements at very low frequencies are required). 


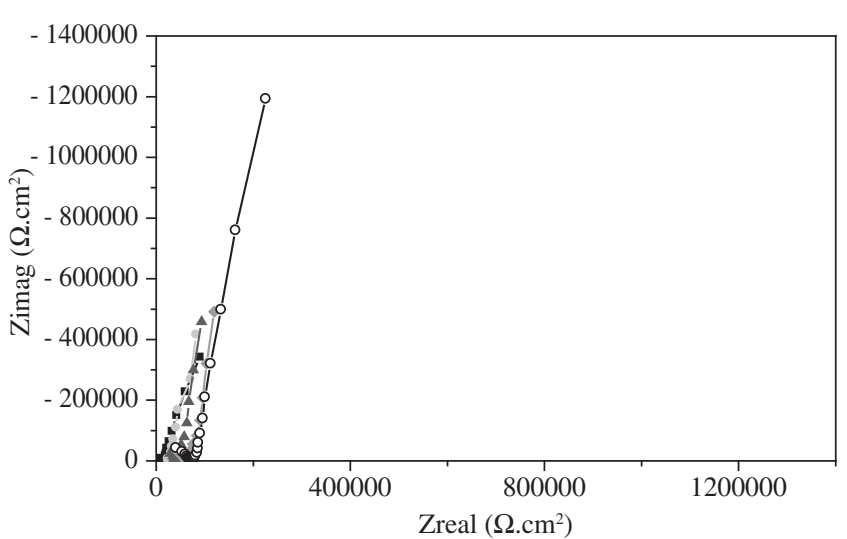

(a)

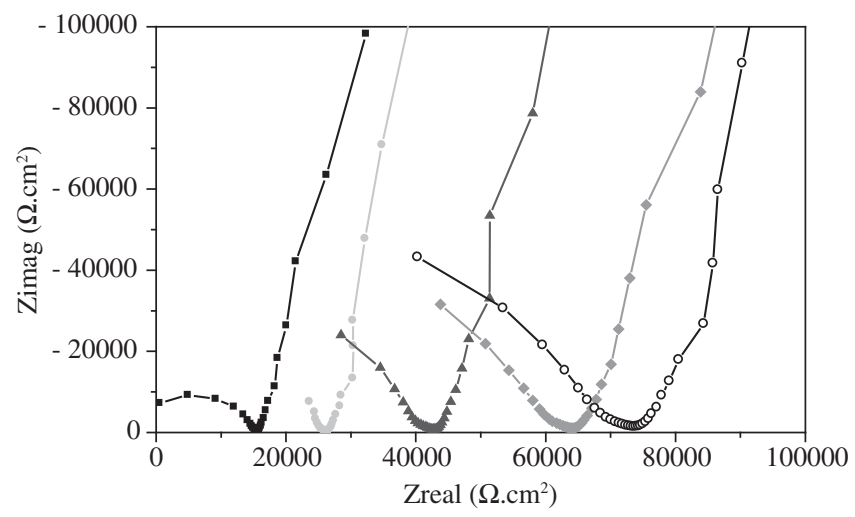

(b)
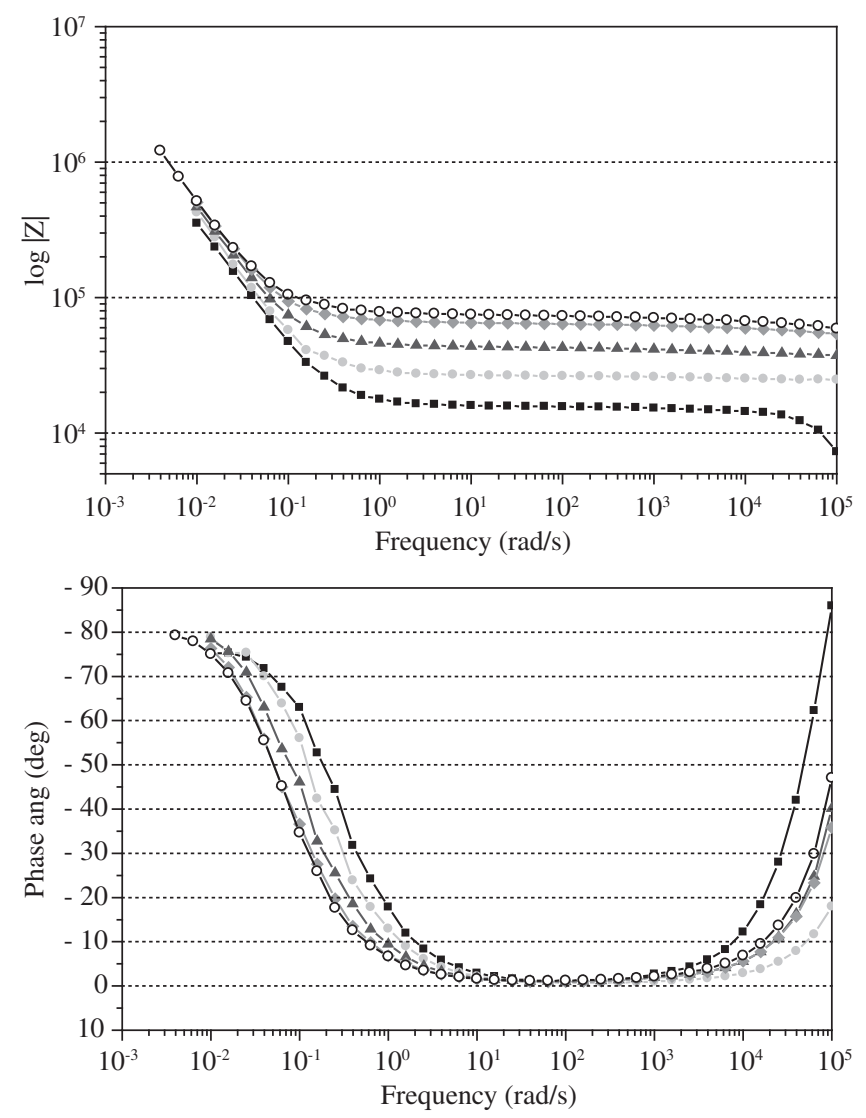

(c)

\begin{tabular}{|c|c|c|}
\hline $\begin{array}{l}\longrightarrow-\text { without agression } \\
-1 \text { month }\end{array}$ & $\begin{array}{l}\longrightarrow 8 \text { months } \\
\smile-15 \text { months }\end{array}$ & $\multimap-22$ months \\
\hline
\end{tabular}

Figure 6. Impedance spectra evolution of concrete sample with silica from rice husk (SHR) during 22 months of immersion in $3.5 \%$ NaCl: a) Nyquist diagram; b) Nyquist diagram - high frequencies; and c) Bode diagrams.

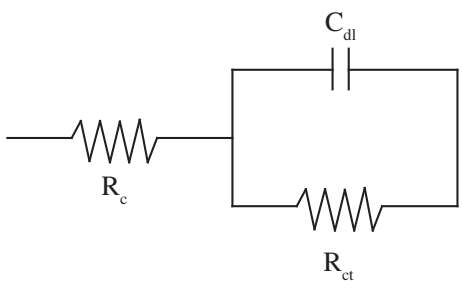

Figure 7. Equivalent circuit.

In spite of the corrosion process not being observed, even after 22 months of drying/immersion cycles of samples in $3.5 \% \mathrm{NaCl}$ solution, it can be observed that there is an increase of durability in the concretes by the increase of the total impedance values and resistivity of the materials. The open circuit potential values also show the passivity of the steel bars, the corrosion potential is more than $-200 \mathrm{mV}$ in relation to the reference electrode copper/copper sulphate, in which the low risk of steel corrosion is considered. Thus, the corrosion resistance of the specimens with and without silica appears to follow the sequence: silica fume $>$ silica extracted from rice husk > control.

It is important to emphasize that due to the high resistivity presented by concretes, ways of minimizing the resistance that can be offered to the signal passage, such as the humidity of the concrete,

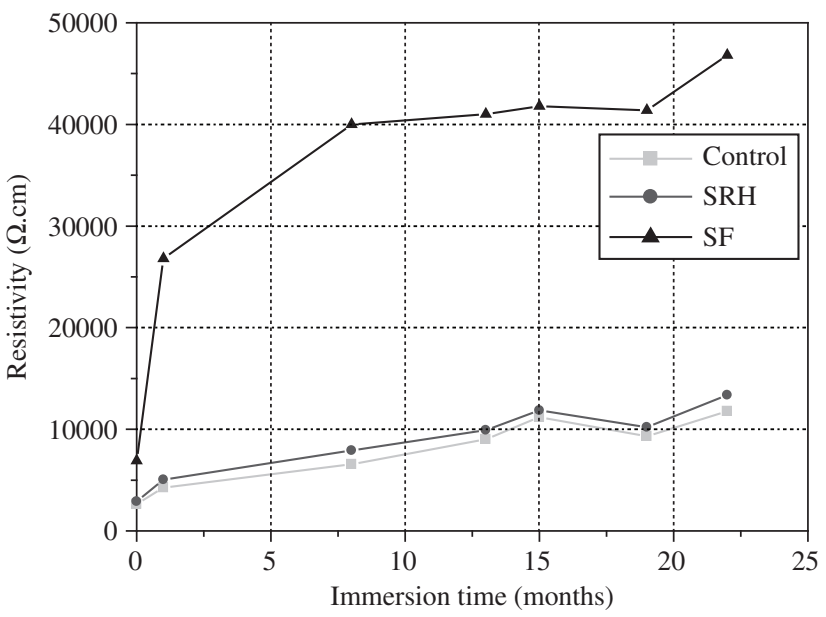

Figure 8. Resistivity evolution of concrete samples partially immersed in a $3.5 \% \mathrm{NaCl}$ solution.

the preconditioned environment of the samples before reading (OCP or EIS), or even larger variation values of potential applied in the system should be sought.

The role of the silicas in concretes was satisfactory, highlighting larger efficiency of SF. The use of both types of silicas is recom- 
mended as they proved to be better than the results obtained in concretes without silica. Both are residues that pollute the environment, but if added to the concrete, improve its properties.

Concrete without silica also presented satisfactory results after 22 months of immersion/drying cycles, indicating that the execution process of concretes is fundamental: rigorous quality control and careful selection of materials, their best combination, their compatibility, mainly of the cement-admixture, their ideal proportions, low water/cement ratio, among other, besides the careful curing process of concretes.

\section{Acknowledgments}

The authors would like to thank FAPESP for their financial support. The authors gratefully acknowledge Prof. Sebastião Kuri and Maria Aparecida G. T. Machado for all the support provided during the project.

\section{References}

1. Broomfield JP. Corrosion of steel in concrete. St. Edmundbury Press Limited; 1997.

2. Mehta PK. Reducing the Environmental Impact of Concrete. Concrete International. 2001; 23(10):61-66.

3. Malhotra VM, Carette GG. Silica fume: a pozzolan of new interest for use in some concretes. Concrete Construction. 1982; May: 445-446.

4. Kayali O, Zhu B. Corrosion performance of medium-strength and silica fume high-strength reinforced concrete in a chloride solutions. Cement and Concrete Composites. 2005; 27(1):117-124.

5. Bentz DP, Jensen OM, Coats AM, Glasser FP. Influence of silica fume on diffusivity in cement-based materials: I. Experimental and computer modeling studies on cement pastes. Cement and Concrete Research. 2000; 30(6):953-952.

6. Aïtcin PC. Concreto de Alto Desempenho. Tradução Geraldo Serra. São Paulo: Editora Pini; 2000.
7. Liborio JBL. Concreto de alto desempenho com sílica ativa da casca de arroz. Projeto Temático FAPESP 98/08112-0; 1998.

8. American Society for Testing and Materials. Standard Method for Half Cell Potential of Uncoated Reinforcing Steel in Concrete. ASTM C876. Annual Book of ASTM Standards. Philadelphia; 1991.

9. Ford SJ, Shane JD, Mason TO. Assignment of features in impedance spectra of the cement-paste/steel system. Cement and Concrete Research. 1998; 28(12):1737-1751.

10. Lay, P. et al. An a.c. impedance study of steel in concrete. Journal of applied electrochemistry. 1985; 15(5):755-766.

11. Montemor MF, Simões AMP, Salta MM. Effect of fly ash on concrete reinforcement corrosion studied by EIS. Cement and Concrete Composites. 2000; 22(3):175-185.

12. Rodríguez P, Ramírez E, Gonzalez JA. Methods for studying corrosion in reinforced concrete. Magazine of Concrete Research. 1994: 46(167): 81-90.

13. Gu, P. et al. A Study of Corrosion Inhibitor Performance in Chloride Contaminated Concrete by Electrochemical Impedance Spectroscopy. ACI Materials Journal. 1997; 94(5):385-394.

14. Associação Brasileira de Normas Técnicas. Cimento Portland de alta resistência inicial. NBR 5733. Rio de Janeiro; 1991.

15. Taylor HFW. Cement chemistry. London: Thomas Telford Edition; 1997.

16. Silva FG, Tommaselli MAG, Liborio JBL, Kuri SE. A influência da umidade na análise de impedância eletroquímica em concretos. XXIV Congresso Brasileiro De Corrosão, 21 a 25 junho; 2004; Rio de Janeiro. Anais; 2004.

17. Lemoine L, Wenger F, Galand J. Sutdy of the corrosion of concrete reinforcement by eletrochemical impedance measurement. Corrosion rates of steel in concrete. ASTM STP 1065. 1990; 118-133.

18. Selmo, SMS. Aço carbono em pastas de gesso de construção: estimativas de taxa de corrosão por impedância e por método gravimétrico conjugado à análise de imagem. Tese (Doutorado) - Escola Politécnica, Universidade de São Paulo; 1997.

19. Cao HT, Sirivavitnanon V. Corrosion of steel in concrete with and without silica fume. Cement and Concrete Research. 1991; 21(2/3):316-324. 